\title{
Família e sobrevivência cotidiana na foz do Amazonas (1944-1964)
}

Sidney da Silva Lobato*

Resumo: Este artigo analisa as estratégias familiares de sobrevivência, existentes na cidade de Macapá, entre 1944 e 1964. O enfoque recai sobre a importância da solidariedade familiar para a subsistência das unidades domésticas. Destacamos que, no interior dessas unidades, as mulheres macapaenses comumente enfrentavam as expectativas dominantes, bem como assumiam a responsabilidade pelo sustento de todos os membros.

Palavras-chave: Família. Sobrevivência. Gênero. Trabalho. Cotidiano.

\section{Introdução}

Em 13 de dezembro de 1952, o jornal carioca Última Hora noticiou que os territórios federais sofriam com a falta de mulheres. Jocosamente, o articulista desse periódico imaginava como reagiriam os "barbados" dos territórios, caso se vissem em "[...] um lugar assim como Jacarepaguá da marchinha carnavalesca, onde mulher era 'mato' e todo mundo podia se arranjar". Também ressaltava que no Amapá a coisa ia pelo mesmo ritmo, pois aí, segundo o censo de 1950, existiam 19.358 homens para 17.614 mulheres (AMAPÁ, 1953a, p. 2). ${ }^{2}$ Esse fenômeno decorria, sobretudo, de movimentos

\footnotetext{
"Doutor em História pela Universidade de São Paulo (USP). Professor de História da Amazônia nos cursos de graduação e pós-graduação da Universidade Federal do Amapá (UNIFAP). Presidente da Seção Amapá da Associação Nacional de História (ANPUH-AP). Atualmente realiza estágio de pós-doutorado em História na École des Hautes Études en Sciences Sociales (EHESS-Paris), com bolsa da Capes. E-mail: lobato.sidney@yahoo.com.br
}

Anos 90, Porto Alegre, v. 22, n. 42, p. 353-373, dez. 2015 
migratórios (intra e inter-regionais) predominantemente masculinos. Era esse o sexo da maioria dos migrantes nordestinos que foram para a chamada Batalha da Borracha (SECRETO, 2007, p. 89). $\mathrm{O}$ êxodo rural ocorrido dentro da região amazônica em meado do século XX também seguia esse perfil. Na Amazônia, muitas vilas e pequenos povoados interioranos eram pontos de partida de homens para as frentes de trabalho abertas nos centros urbanos em expansão, como Macapá.

Macapá, no início de 1944, ganhou o status de capital do Território Federal do Amapá. Naquele momento, no entanto, ela era uma vila de algumas centenas de habitantes, abalada pela crise da borracha amazônica do início do século XX (LOMBAERDE, 1987, p. 8). As construções realizadas pelo governo territorial trouxeram novo fôlego para a combalida economia macapaense. Em números arredondados, Speridião Faissol nos fornece uma síntese do vertiginoso crescimento populacional macapaense nesse contexto: "[...] a população de Macapá, que em 1940 era de 2 mil habitantes, foi crescendo para 10 mil em 1950, 25 mil em 1960 e para os seus atuais [1966] 40 mil”. Faissol afirma que este "exagerado crescimento" derivou da criação do Território Federal do Amapá e das ações do governo federal na região. As novas condições de assistência e de vida existentes em Macapá foram o principal foco de atração para as populações das ilhas paraenses vizinhas (FAISSOL, 1966, p. 26). Paraenses e nordestinos compuseram a maior parte da onda migratória que gerou esse boom populacional.

Moradores dos arquipélagos situados na foz do rio Amazonas buscavam, na capital do Amapá, oportunidades para ganhar algum dinheiro e de (com ele) poder melhorar a vida de suas famílias. É muito importante situar essas migrações como parte das estratégias formuladas pelas famílias na busca por meios de subsistência. Nas áreas rurais da Amazônia, como nas de outras regiões, a família extensa, que inclui, além de pais e filhos, a parentela próxima, era e ainda é a unidade social fundamental na luta cotidiana pela sobrevivência. De modo geral, no espaço doméstico, forma-se uma célula econômica que combina diferentes modalidades de trabalho (LIMA, 2006, p. 145-172). Mesmo no período em que parecia que as famílias amazônicas devotavam todas as suas forças à extração 
do látex (1850-1912), é possível encontrar uma combinação de várias atividades econômicas. $\mathrm{Na}$ chamada região das ilhas do Pará - incluindo o arquipélago do Marajó, os vales do Xingu e do Jari, alcançando ainda os rios Capim, Guamá, Acará e Moju - predominou a extração da borracha combinada com a coleta de outros produtos florestais, a agricultura de subsistência, a pesca etc. (OLIVEIRA FILHO, 1979, p. 124).

Muitas atividades rurais eram sazonais. Umas estavam mais ligadas à subsistência e outras à comercialização (aquisição de bens não diretamente gerados pela unidade doméstica). A divisão de tarefas era disciplinada por normas costumeiras relativas ao sexo e à idade dos membros da família (CASTRO, 2006, p. 176). Uma vez na cidade, o migrante se deparava com outros sistemas normatizadores, que tentavam delimitar ainda mais os espaços de atuação de homens de um lado e de mulheres do outro. O objetivo deste artigo é, a partir da investigação do universo das práticas sociais das mulheres, apontar as incongruências entre as normatizações e o vivido nas relações de gênero ocorridas em Macapá, entre 1944 e 1964. Ao perscrutarmos esse universo, objetivamos também evidenciar o papel vital que as mulheres desempenhavam no interior da economia familiar. Nesse sentido, uma primeira inferência que resulta do contato com a documentação é a seguinte: todos os membros (exceto as crianças muito pequenas) eram mobilizados para a criação dos meios de sobrevivência da família.

\section{Unidades domésticas e estratégias de sobrevivência na Amazônia}

Pais de prole numerosa dividiam com ela o peso das fainas diárias. A maior parte dos sujeitos identificados nos processos judiciais que analisamos começou a trabalhar entre nove e doze anos de idade. Tal começo não era visto como precoce, mas como um imperativo decorrente dos riscos à sobrevivência familiar. $\mathrm{O}$ antropólogo estadunidense Charles Wagley, após investigar o cotidiano dos moradores da comunidade de Gurupá, chamada por ele de Itá, no final da década de 1940, comentou que "[...] essa teoria 
Família e sobrevivência cotidiana na foz do Amazonas...

de que a criança não deve executar trabalhos braçais é puramente aristocrática" e que "[...] a situação econômica instável da maioria dos habitantes de Itá, a instabilidade de suas relações conjugais, e a consequente desunião das famílias não proporcionam uma situação propícia à proteção da criança” (WAGLEY, 1957, p. 247). Teixeira de Mello destacou que, nos interiores amazônicos, as crianças (em geral analfabetas) abraçavam "[...] a profissão paterna, empunhando, ainda adolescentes, a espingarda que abate a caça, o terçado que abre veredas, a 'faca' que corta a seringa ou o machado que derruba a mata” (MELLO, 1956, p. 56).

$\mathrm{O}$ aprendizado dos trabalhos era um dos mais importantes legados que os pais pretendiam deixar para seus filhos, pois seria um instrumento fundamental para a subsistência, numa vida marcada pela insegurança estrutural (SAVAGE, 2004, p. 25-48). Não raramente, os trabalhos infantis eram estafantes. Por exemplo, Raimundo Pereira Picanço, aos doze anos, apanhava dez latas de açaí por dia (ARQUIVO DO FÓRUM DA COMARCA DE MACAPÁ [doravante: AFCM], 1957a, p. 12). As meninas interioranas, além dos trabalhos nos roçados e na floresta, ajudavam as mães nos variados afazeres domésticos. Às vezes, carregavam outra criança cujo tamanho se aproximava do seu. Em Macapá, os garotos pobres se convertiam em pequenos vendedores, moleques de recado e aprendizes dos mais diversos ofícios - como Izidoro Palmeirim, de 14 anos, que trabalhara como aprendiz de sapateiro e fazendo pequenos carretos na área portuária chamada de Doca da Fortaleza (AFCM, 1952a, p. 6). Muitos filhos contribuíam para o sustento da unidade doméstica até se casarem e, alguns, mesmo depois disso (AFCM, 1953a, p. 18).

Quando os ganhos obtidos não eram suficientes para o sustento da família, uma das possibilidades abertas aos pais era ceder os filhos para a adoção. Wagley ressaltou: “[...] a frequência da adoção de crianças na região amazônica está diretamente ligada à pobreza e aos altos índices de mortalidade da população". E ponderou: "a vida humana é absolutamente incerta na Amazônia” (WAGLEY, 1957, p. 251). A adoção ocorria, portanto, dentro de um consenso em torno da busca de melhores condições de vida para as crianças. Em junho de 1960, a professora Lucimar Alves (moradora do bairro macapaense 
chamado de Favela) declarou à autoridade policial que, em maio de 1959, precisando de uma empregada, "[...] foi informada por uma de suas alunas que uma certa senhora, moradora às proximidades da Escola Doméstica, tinha uma filha que desejava empregar-se [...]" e que "[...] procurou então dita senhora e depôs [sic] de expôr-lhe a razão de sua visita, a mesma entregou à declarante a menor, não como empregada mas para que dela ficasse responsável pela sua instrução e criação”. Maria Benedita Batista Ferreira dos Santos foi levada no mesmo dia pela professora Lucimar Alves e em sua casa "[...] passou a ser tratada como filha e a merecer toda a atenção e consideração da declarante e de seu espôso" (AFCM, 1960a, p. 13).

A cessão de um filho para a adoção era comumente uma medida extrema, evitada até o limite do possível. É o que nos sugere, por exemplo, o relato da moradora do Laguinho Josefa Lina Ramos: "[...] eu lavava pra fora, eu ia pra roça, eu fazia limpeza na casa de uma qualquer pessoa, porque eu não fiquei acomodada depois que o meu marido morreu, sofrendo com meus filhos. E não dava nenhum, pois eu não tinha coragem". Lina Ramos afirmou que pessoas compadecidas pediram seus filhos para adoção e ressaltou: "se a casa não fosse minha era capaz de dar [...]. Mas, eu digo: eu não dou nenhum". ${ }^{3} \mathrm{Na}$ leitura dos processos criminais percebemos que a opção pela cessão dos filhos estava muitas vezes associada à morte de um dos pais. A moradora de Conceição, no rio Piririm, Maria Madalena Dias tinha sete anos quando sua mãe faleceu, em 1940. Quando isso aconteceu, o pai a entregou ao padrinho (AFCM, 1949a, p. 4). Em 1946, a professora Oscarina Silva recebeu a menor de 10 anos e órfã de pai, Maria Ludovina Quaresma, de sua mãe, no povoado de Igarapé Miri (Pará). No ano seguinte, a menina se mudou com a tutora para Macapá (AFCM, 1952b, p. 5).

No âmbito da geração dos meios para a sobrevivência familiar, as estratégias envolvendo uma ampla mobilidade espacial se afiguravam, à primeira vista, como algo inexoravelmente destinado ao uso masculino. Às vezes, o movimento migratório era feito apenas pelo pai e outras, pela família inteira. Vejamos o caso de João Pernambuco que, em 1924, foi morar na Ilha dos Porcos, onde, em 1929, amasiou-se com Rosa, com quem se casou em 1937. Quando casaram, já tinham seis filhos e depois vieram mais dois. 
Em depoimento dado na delegacia de Macapá, em março de 1945, João Pernambuco afirmou que, desde 1938, "[...] tem trabalhado, periodicamente, em Macapá, para onde se transportava sosinho [sic], deixando a mulher e os filhos na Ilha dos Porcos; que esse serviço periódico consistia na faiscação de ouro, e, terminado, regressava à sua casa [...]”. Em 1942, por dificuldades da vida, João Pernambuco foi com toda a sua família para o vale do rio Araguari, para trabalhar no corte da seringueira. Entretanto, aí passou só um verão, pois o serviço não fora compensador. Transferiu-se "[...] mais para baixo, no verão seguinte". Em agosto de 1943, foi com sua família morar e extrair látex em Trapichinho, onde permaneceu até fevereiro de 1944. De fevereiro a julho daquele ano, ficou em Porto Grande, trabalhando num roçado que abriu em sociedade com o gerente comercial Gerino Porto, com quem passou a morar, juntamente com sua família (AFCM, 1945, p. 7-10).

João Pernambuco e sua família combinavam a atividade agrícola com o extrativismo - a primeira, no período chuvoso (o inverno amazônico, que ocorre no primeiro semestre do ano) e o segundo, durante o estio (segundo semestre). A combinação de várias atividades produtivas era algo comum na Amazônia. Vimos anteriormente que João Pernambuco se aventurava também no trabalho de garimpagem. Num inquérito policial de 1943, Miguel Antonio Martins se apresentou como garimpeiro e seringueiro. Porém, na leitura dos autos, ficamos sabendo que, além disso, ele era lavrador (AFCM, 1943). Em fevereiro de 1948, o morador de Soure ${ }^{4}$, Raimundo Vilas Novas afirmou diante do juiz da Comarca de Macapá que, como agricultor, era "[...] no espaço que medeia entre a plantação e a colheita, aproveita-a para trabalhar como embarcado" (AFCM, 1948, p. 28). Os trabalhadores interioranos também podiam se dedicar temporariamente aos serviços de vaqueiro e de zelador de fazenda, como o lavrador Genaro Brazão da Silva o fez em 1944 (AFCM, 1946a, p. 2-36). O aproveitamento das possibilidades econômicas em áreas agricultáveis, de seringais, de veios auríferos, de fazendas, de caça e de pesca implicava num esforço de deslocamento e de adaptação a situações muito diferentes.

Rápidas idas à cidade também compunham o rol da movimentação masculina, visando à sobrevivência familiar. Muitos 
trabalhadores das ilhas da área da foz do Amazonas e dos povoados rurais do Amapá iam periodicamente a Macapá para vender o produto de seus trabalhos. O Relatório do delegado Oswaldo Viana, apresentado num inquérito de março de 1952, traz as seguintes considerações relativas a esse tema: os indiciados "[...] são dêsses muitos cabôclos amazonenses que, no trabalho das lavouras rotineiras e desprotegidas ou na extração desorientada do latex das seringueiras nativas, na procura das sementes oleaginosas" vão vivendo como "[...] eternos párias da malfadada Planicie Amazônica" (grifo do autor). E no parágrafo seguinte: "a cachaça é o derivativo dos seus prazeres, digamos, sua alegria, e esta, via de regra, esta consubstanciada na viagem em igarité (reboque entre nós), do sítio da produção ao mercado consumidor, onde, então, os parcos apurados das suas vendas, são aplicados na aquisição daquela bebida [...]" (AFCM, 1952c, p. 34). $\mathrm{O}$ crescimento da capital amapaense e de sua praça comercial concorreram para que a cidade polarizasse cada vez mais os fluxos comerciais de vilas e povoados próximos.

\section{As mulheres e a urdidura da sobrevivência cotidiana}

A venda da produção da unidade doméstica era uma atividade predominantemente masculina. A demarcação da comercialização dos frutos do trabalho da família como uma atividade de homens reforçava o controle masculino sobre a receita familiar (WAGLEY, 1957, p. 225). Mas, classificar rigidamente as mulheres como seres aprisionados no espaço doméstico, atribuindo somente aos homens as atividades ligadas à mobilidade espacial, é algo que se choca com numerosas evidências. Não poucas mulheres migraram de pequenas cidades e povoados da Amazônia Oriental para Macapá, a fim de se empregarem como domésticas e poderem ajudar suas famílias. A mãe de Terezinha Braga Martel, uma menina de 15 anos, esteve residindo na capital do Amapá em 1948. Daí se retirou para o Gurupá no mês de maio de 1948, deixando sua referida filha como serviçal na residência de James Lionel Burnett (AFCM, 1949b, p. 4). Maria de Jesus Padilha viera com o amásio para Macapá, em 1952, e aí começou a trabalhar como doméstica na casa da professora 
Elza Cunha. Padilha mantinha correspondência regular com a mãe, que ficara em Cametá. Numa carta de junho de 1953, a genitora de Padilha afirma: "arrecibi o dinheiro que mandaste" (AFCM, 1953b, p. 6 e 10). Eram duzentos cruzeiros.

O crescimento do número de funcionários públicos solteiros e de funcionárias públicas (enfermeiras, professoras e outras) que passavam boa parte do dia no trabalho externo ao lar criou uma grande demanda de empregadas domésticas em Macapá, no período estudado. Em geral, elas tinham entre 15 e 18 anos e moravam com seus patrões. Algumas domésticas, em pouco tempo, trabalharam em várias casas. O que se explica em parte pela precariedade da vinculação ao trabalho e em parte pela gama de oportunidades existentes. Maria Creuza Lucas Pena, por exemplo, começou a trabalhar como doméstica na casa de Abdias Bezerra Filho em 1957, onde permaneceu durante 6 meses. Depois de ficar 3 meses desempregada, foi trabalhar para Severino Gomes de Almeida (conhecido como Pernambuco), emprego que durou 3 meses (época em que tinha 16 anos). Então, Maria Creuza saiu da casa de Pernambuco e voltou à casa de sua genitora. Passados cerca de dois meses, empregou-se na casa do casal Jorge e Estelita Batista, onde permaneceu de 1960 até 1961. Daí foi trabalhar na casa do Dr. Viana, em Porto de Santana - durante 6 meses. Após isso, ela voltou à casa de Jorge Batista e, decorridos 8 meses, foi para a casa de sua tia Adelaide, no bairro de Nossa Senhora do Perpétuo Socorro. Por fim, foi trabalhar no Bi-campeão bar, na Avenida Coaracy Nunes, na doca da Fortaleza (AFCM, 1964, p. 10).

Antes de virem para Macapá, quase todas essas empregadas domésticas eram lavradoras e extrativistas. Em certas ocasiões, as mulheres adultas podiam assumir a responsabilidade total sobre o trabalho nas roças. Como já ressaltamos, a unidade familiar inteira se dedicava tanto à agricultura quanto aos extrativismos. Com base nas observações feitas em Gurupá, Wagley destacou que: “[...] a roçagem do terreno, a queimada e a coivara são trabalhos dos homens; mas as mulheres ajudam os maridos na plantação e, algumas vêzes, na remoção de ervas daninhas, bem como na colheita da mandioca e na fabricação da farinha" (WAGLEY, 1957, p. 107). No tocante ao trabalho feminino nos seringais, a antropóloga Lígia Simonian 
argumenta: "por ocasião do boom da borracha em meados dos anos de 1940, a presença de mulheres nos seringais passou a ser notada com mais frequência”. E ela acrescenta: "[...] foi ainda durante esse boom produtivo, que muitas famílias do baixo Amazonas foram levadas para o sul do Amapá, quando mulheres e meninas com experiência no corte de seringa seguiram juntas e ali passaram a trabalhar nos seringais" (SIMONIAN, 2001, p. 86).

Portanto, nas áreas afastadas dos centros urbanos, as mulheres executavam trabalhos fundamentais para a sobrevivência familiar. Uma vez em cidades como Macapá, era no setor de serviços que elas mais estavam presentes. Segundo o censo de 1950, das 1.013 pessoas que trabalhavam na "prestação de serviço" no Amapá, 598 eram mulheres (IBGE, 1955, p. 13). Em 1960, trabalhavam nesse setor 1.209 homens e 1066 mulheres. Conforme destacamos antes, muitas mulheres migrantes se empregaram como domésticas. Muitas outras passaram a ajudar no sustento da família através da lavagem de roupas para outrem (IBGE, 1968, p. 159-172). Uma dessas lavadeiras era Odete Maciel (paraense de 21 anos). Em inquérito de abril de 1952, ela declarou "[...] que, ocupa[va] a cosinha de uma casa situada no bairro do Trem, de propriedade de Ocimar Marialves de Melo" e que "[...] paga[va] de aluguel ao referido Ocimar, cem cruzeiros (Cr\$ 100,00) mensais". Odete Maciel informou ainda que residia na companhia de três filhos seus, "[...] todos menores, o mais velho com cinco anos e o último de seis mezes de idade" e que se encontrava devendo dois meses de aluguel do referido cômodo. Isso porque estava aguardando receber os pagamentos da lavagem de roupa dos seus diversos fregueses (AFCM, 1952d, p. 7). As lavagens de roupa possibilitavam a uma mulher com vários filhos pequenos, como Odete Maciel, não abdicar da educação deles.

O caso de Odete Maciel também indica a existência em Macapá de várias configurações familiares. Seria um grave equívoco imaginar a existência de apenas um arranjo familiar. Muitos eram os casos de famílias monoparentais. Outro grande erro seria imaginar que o espaço de convívio familiar excluía qualquer possibilidade de tensão em prol da busca solidária da sobrevivência. Várias formas de conflito surgiam no interior das unidades domésticas e neste estudo apontaremos apenas algumas delas. $\mathrm{O}$ abandono do 
cônjuge era uma alternativa que estava no horizonte das mulheres violentadas e, por isso, insatisfeitas. Em fevereiro de 1952, a empregada doméstica Cezarina Silva (paraense de 20 anos e residente na doca da Fortaleza) depôs em inquérito que a partir de certo tempo passara a brigar com seu amásio por causa dos ciúmes dele e que havia dois meses resolvera deixá-lo, "[...] indo empregar-se em casa do doutor Promotor Público desta Comarca” (AFCM, 1952e, p. 11). Outro exemplo é o de Maria Morais (paraense de 18 anos e residente no Laguinho) que, em março de 1953, era casada havia 4 anos. Ela depôs que havia 2 anos que seu esposo a maltratava, chegando a espancá-la duas vezes (ambas motivadas pelo fato de a depoente ter chamado a atenção do agressor por este ter chegado em casa "em horas fora de costume"). Na segunda vez, Maria Morais enviara uma carta a seu pai, na qual relatava o que vinha sofrendo, "[...] solicitando providencias para voltar ao convívio paterno" (AFCM, 1953c, p. 5).

O que se sobressai nesses e em outros casos é a atitude insubmissa da mulher diante do marido (ou amásio). Algo que contrasta - como evidenciaremos adiante - com o que era apregoado no discurso hegemônico do pós-1944. Quando os companheiros, ao invés de concorrer para a subsistência da família, tornavam-se um peso para esta, várias mulheres não hesitavam em abandoná-los. Em abril de 1953, Mercedes Lima, estudante paraense de 13 anos, declarou à Polícia que sua mãe abandonara o lar. Esclareceu "[...] que, o genitor da declarante não entrava com o suficiente para o sustento da casa, rasão $[s i c]$ porque sua mãe trabalhava fora e finalmente resolveu abandoná-lo". A mãe de Mercedes, paraense de 32 anos e residente no Trem, declarou que deixara suas filhas na companhia de uma senhora com quem ela residia havia algum tempo e que o motivo era o fato de "[...] seu esposo não corresponder com o necessário para a manutenção da casa, dizendo mais que, se tem alguma coisa era porque trabalhava e quem praticamente sustentava a casa era ela declarante, não sabendo dizer onde seu esposo metia o dinheiro que ganhava" (AFCM, 1953d, p. 7-8). Em agosto de 1953, a agricultora cearense de 49 anos, Maria Viana, residente no $\mathrm{km} 6$ da rodovia Macapá-Fazendinha, representou contra Raimundo Geroncio e afirmou que não mais pretendia viver com ele, entre 
outras coisas, “[...] por ser pessôa de máu procedimento, vadio e dando-se ao vicio de embriaguês e quando está neste estado ameaça a representante bem como suas filhas, de morte”. O vizinho Simplício dos Santos acrescentou que Geroncio era preguiçoso, apesar de ter "uma mulher trabalhadora e que muito procura ajuda-lo; que até uma única róça que tem é trabalho de dona Maria com as filhas" (AFCM, 1953e, p. 4, 28).

O abandono dos amásios era um modo das mulheres afirmarem seu protagonismo numa cidade que, ao mesmo tempo, atribuía-lhes um papel dependente e desafiava cotidianamente sua sobrevivência. Mesmo sem romper o vínculo com os companheiros, as mulheres não raramente assumiam a chefia do núcleo familiar. Era o que poderia ocorrer quando o cônjuge adoecia. Mais comum (devido à citada mobilidade masculina) era o caso de mulheres que administravam a casa e os negócios da família durante as longas viagens dos maridos. Assim, em outubro de 1952, Sebastiana Pantoja, paraense de 25 anos e residente na vila de Porto Grande, estava tomando conta de uma casa comercial que pertencia a seu esposo José Pantoja, que estava ausente (AFCM, 1952f, p. 3). Outra situação em que as mulheres passavam a gerenciar a unidade doméstica era a da morte de seus companheiros (AFCM, 1946b). A variedade de situações criadas no âmago do enfrentamento da insegurança estrutural não autoriza a generalização do absoluto domínio masculino na unidade doméstica. Pelo contrário, são numerosas as evidências de que as mulheres comumente assumiam o protagonismo no sustento e na definição dos destinos das suas famílias. Mesmo quando se achavam numa posição subalterna, não viviam na condição de simples dependentes, mas de colaboradoras assíduas.

Além de exercerem atividades pouco remuneradas - quando eram domésticas, lavadeiras, carvoeiras, costureiras, comerciárias etc. - algumas mulheres conseguiam ascender socialmente, fosse através do ingresso no funcionalismo público, principalmente como enfermeiras e professoras, fosse através de investimentos em pequenos negócios. Este foi o caso de Dona Nené, que administrava uma pensão (AFCM, 1946c, p. 9, 29). Joaquina Menezes de Oliveira (de 34 anos, residente na Rua General Gurjão s/n) fornecia refeições a diversos rapazes que trabalhavam no Palácio do Governo, cobrando de cada 
o valor mensal de Cr\$1.300,00 (AFCM, 1957b, p. 4, 15). Através de outro processo judicial, tomamos conhecimento de que a esposa do guarda territorial Onésimo Mendes (paraense de 33 anos e residente no Laguinho) era sócia de Eneas Pacheco no bar Pina, onde também eram servidas refeições a trabalhadores (AFCM, 1960b, p. 10).

\section{A mulher e a família segundo o discurso hegemônico}

As trabalhadoras apresentadas nessas linhas, e tantas outras que existiram na Macapá de outrora, deparavam-se com o discurso que asseverava que elas estavam fora do lugar certo. Na década de 1940, o Estado Novo orquestrou uma série de ações com o intuito de promover a efetivação de um padrão familiar tido como ideal. Rompendo com o modelo dominante na República Velha (de instituições particulares, subsidiadas pelo Estado, voltadas para o apoio a mães e crianças pobres), no ano de 1940, o governo estadonovista criou o primeiro programa estatal de proteção à maternidade, à infância e à adolescência. Esse programa fora levado a cabo pelo Departamento Nacional da Criança (DNCr) - órgão do Ministério da Educação e Saúde, que fomentou a criação de postos de puericultura em todo o Brasil. Em tais postos, as mães podiam receber orientações médicas, da gravidez até que a criança iniciasse a fase escolar. Em 1942, foi criada a Legião Brasileira de Assistência (LBA), destinada a prestar vários tipos de assistência aos empobrecidos. Por meio dessas instituições, o governo federal difundia a ideia de que a mulher que trabalhasse fora de casa deixaria seu lar instável e seus filhos, vulneráveis a influências moralmente nocivas. Criticavamse as trabalhadoras que deixavam sua prole com vizinhos ou sob a responsabilidade do filho mais velho (PEREIRA, 1999, p. 181-182).

O modelo ideal de família era aquele no qual o marido trabalhava fora e era o chefe; a esposa-mãe exclusivamente se dedicava a cuidar da casa e dos filhos, que permaneciam na escola até estar prontos para trabalhar. No Amapá, o primeiro governo territorial abraçou as diretrizes emanadas do DNCr. Em 18 de agosto de 1944, foi instalada a Comissão Territorial da LBA (NUNES, 1946, p. 138-139). Em Macapá e nas demais sedes municipais, a Legião distribuía latas 
de leite, pacotes com vários gêneros alimentícios, enxovais para gestantes e recém-nascidos, mosqueteiros, redes, bem como remédios (AMAPÁ, 1947, p. 2; AMAPÁ, 1949, p. 10). Vinculado à LBA, o Posto de Puericultura Iracema Carvão Nunes foi inaugurado em outubro de 1945, com a finalidade de oferecer às mães um conjunto de meios para a formação física, mental e moral da criança. O propósito principal do Posto era reduzir a mortalidade infantil através de uma ruptura com os "processos rotineiros", que incluíam a atuação de parteiras e amas de leite (AMAPÁ, 1945, p. 1). Para tanto, esse órgão governamental contava com: consultório de higiene pré-natal; consultório pós-natal; consultório de higiene infantil; consultório de imunizações; lactário e cantina maternal - que oferecia sopas e merendas às gestantes e nutrizes (AMAPÁ, 1951a, p. 7).

Anualmente, o governo territorial realizava a Semana da Criança. Na ocasião, noções relativas à proteção da criança frente às ameaças de influências nocivas eram difundidas, por meio de palestras e concursos (AMAPÁ, 1951b, p. 1). A ideia de que a criança era um ser puro que deveria ser preservado do contágio dos males sociais vinha ganhando força no Brasil desde o final do século XIX (SCHUELER, 1999, p. 59-84). A família (idealizada) deveria ser um núcleo protetivo para a criança. Em maio de 1948, o jornal Amapá publicou um texto intitulado "A família". Nele, afirmava-se que a criança não poderia simplesmente crescer entre outras crianças, pois "[...] é necessário, antes de tudo, [um] ambiente apropriado para o seu desenvolvimento e esse ambiente, onde a criança deve crescer e se formar é a família". E adiante: "os pais vêm que agora, como no seu tempo de garotos, os filhos tem [sic] o mesmo direito a um lar, à criação e educação que os pais devem dar" (AMAPÁ, 1948, p. 2.). O modelo de família então estandardizado (protetiva e que direcionava os filhos unicamente para os estudos escolares), chocava-se com as necessidades reais das famílias da classe trabalhadora, que, em muitos casos, não podiam abrir mão do trabalho dos menores.

A Igreja Católica defendia um modelo de família que coincidia com o do governo. À mãe cabia integralmente a educação dos filhos. Aquilo que era dito nos púlpitos das igrejas, podemos ler nas páginas do jornal $A$ voz católica, como demonstra este trecho de um artigo de fevereiro de 1960: "[...] é no aconchego do lar, no regaço da mãe 
que se apreende a honestidade, o temor de Deus, o respeito de seu semelhante, o amor ao dever [...]” (A VOZ CATÓLICA, 1960a, p. 4). Os textos deste periódico davam grande ênfase à quase exclusiva responsabilidade das mães em relação à boa educação da prole (A VOZ CATÓLICA, 1963, p. 2). Dirigindo-se às "queridas mães”, o articulista do semanário $A$ voz católica ressaltava: aos vossos fillhos "vós deveis ensinar-lhes o respeito, a veneração, a discreção [sic], corrigindo oportunamente e dando bom exemplo" (A VOZ CATÓLICA, 1960b, p. 4). Pensavam os membros do clero macapaense que, com tamanha responsabilidade, a mulher não deveria cogitar trabalhar fora de casa. Ela deveria estar liberada para se dedicar com o afinco necessário à sagrada missão de formar os futuros homens de bem. Para tanto, os pais deveriam assumir sozinhos o fardo de labutar para adquirir os provimentos necessários ao lar.

Quando os articulistas do periódico da então Prelazia de Macapá se dirigiam aos pais, os temas eram sempre relativos aos papeis para eles idealizados. Num dos números de março de 1960, lemos: "[...] o pai deve ser econômico, pois ele é responsável pelo futuro da família, que se pode prover só com um vivo senso de economia” (A VOZ CATÓLICA, 1960c, p. 4). Absolutamente dependente do homem para a sua sobrevivência, a mulher assim representada deveria ser obediente e resignada na sua relação matrimonial. Nesse sentido, um articulista exortava: "[...] a mulher, casando-se, deve obedecer ao marido. As chamadas moças modernas, com idéias erradas acerca da independência e emancipação, não casem, porque isso seria para a sua derrota, a infelicidade da família, a desgraça da sociedade" (A VOZ CATÓLICA, 1960d, p. 4). A mulher que trabalhava fora do lar era apresentada pelo articulista José Benevides como um ser que se desviava dos desígnios divinos: "[...] desde que a mulher foi expulsa do santuário sagrado do lar e atirada na rua e na miragem aliciadora do emprêgo por essa carcomida civilização do século XX, começou a fugir-lhe a noção de sua verdadeira missão" (A VOZ CATÓLICA, 1960e, p. 4). Para se manter fiel à sua vocação de mãe e de esposa, a mulher deveria abrir mão do espaço público, que era visto como fator masculinizante (A VOZ CATÓLICA, 1961, p. 2). Para Benevides, o apagamento das rígidas fronteiras que demarcavam os territórios do homem e da mulher - supostamente 
fruto da avalanche demolidora da "carcomida civilização" - deveria ser combatido através da recristianização da família.

Governo territorial e clero local se uniram em torno de ações cuja finalidade era fomentar a adoção pelos moradores e moradoras de Macapá do modelo descrito. Em agosto de 1951, o governo instalou a Escola Doméstica de Macapá que, desde então, foi dirigida pelas freiras da Ordem das Irmãs da Caridade das Santas Capitânea e Gerosa, de Milão - Ordem que também era conhecida pelo nome de Irmãs de Nossa Senhora Menina (NEGRI, s/d., p. 35). A Escola Doméstica atendia alunas em regime de internato - sobretudo "órfãos desamparadas" do interior do Território - e de externato - "quantas senhoras e senhoritas que desejam aprender um curso doméstico" (AMAPÁ, 1952a, p. 4). No título de um artigo de janeiro de 1952, o jornal Amapá evidenciou o objetivo desse educandário: "Escola Doméstica de Macapá: aprimorando a mulher amapaense para a nobre direção do lar”. Definindo o espaço doméstico como aquele onde a mulher deveria (saber) atuar, a instituição buscava fortalecer uma divisão sexual do trabalho.

A Escola Doméstica foi concebida como uma "trincheira moral e espiritual" no combate aos arranjos familiares considerados desviantes (AMAPÁ, 1952b, p. 4). A Nova Lei Orgânica do Ensino Secundário, de 1942, afirmava: "[...] é recomendável que a educação secundária das mulheres se faça em estabelecimentos de ensino de exclusiva freqüência feminina [...]; a orientação metodológica dos programas terá em mira a natureza da personalidade feminina e bem assim a missão da mulher dentro do lar" (MEC, 1942, p. 7). Na Escola Doméstica, as alunas eram preparadas para serem "[...] exímias donas de casa, conhecendo todos os segredos que fazem do lar a pedra de toque da organização da família e da sociedade" (AMAPÁ, 1953b, p. 2). Para tanto, as alunas aprendiam corte-costura, tricô, bordados, crochês e culinária. A união de esforços do governo janarista e da Igreja pelo bom funcionamento da instituição derivava, entre outros fatores, do ideal comum de moral familiar. Desejamos enfatizar que, na década de 1950, apesar do espaço crescente que as mulheres do Amapá (e de todo Brasil) conquistavam no mercado de trabalho, concepções androcêntricas e patriarcais ocupavam uma posição hegemônica. 
Este modelo de mulher devotada ao lar e subserviente ao marido derivava do postulado de que o feminino era o sexo frágil. Essencialmente sensível, a mulher deveria ser tutelada (protegida) pelo sexo forte (AMAPÁ, 1964, p. 2). Tú és grande, mulher! é um artigo do jornal $A$ voz católica no qual podemos ler: "[...] a mulher é

$\infty$ símbolo e sinônimo de ternura, delicadeza, dedicação até o sacrifício", (6) enquanto "[...] o homem, geralmente, encarna a força, a vontade m decidida a triunfar de tudo e de todos" (A VOZ CATÓLICA, 1960f, p. 4). Negar a própria fragilidade e, portanto, dependência, seria ir contra sua natureza. Algo comum aos discursos governamental e eclesiástico é a preocupação com as tendências modernizantes, que, supostamente, ameaçavam tais representações de gênero. Assim, no já citado artigo Feminismo exagerado, Benevides afirmara: “[...] hoje em dia, vemos com tristeza, como as modernas filhas de Eva aparecem na sociedade, querendo em tudo rivalizar com o homem, através de uma desenvoltura de maneiras e atitudes de independência próprias sòmente do 'sexo forte”' (A VOZ CATÓLICA, 1960e, p. 4).

\section{Considerações finais}

Médicos, professores, policiais, juízes, promotores, padres e outros agentes eram chamados a fazer um esforço para que a moral familiar fosse uma diretriz efetiva para as práticas dos sujeitos históricos. Muito passional e suscetível às influências perturbadoras da modernização, a mulher deveria, então, permanecer sob a tutela e a vigilância de instituições reguladoras. No discurso hegemônico, mulher emancipada aparece quase sempre como sinônimo de mulher perigosa. Uma vez púbere, os pais deveriam sempre mantê-la diante de olhares atentos e intimidadores. Quando chegada a hora, ela passaria da tutela dos pais para a do o marido, desconhecendo em absoluto o estado de ser emancipada. O casamento era o momento em que a mulher deveria - ainda segundo o discurso hegemônico - oferecer sua honra e sua virgindade ao esposo.

Porém, estudos sobre relações de gênero na Amazônia têm demonstrado que as classes proprietárias eram muito mais permeáveis 
a essas normatizações do que as classes trabalhadoras (ALVARES, 1994, p. 220-223; CANCELA, 2006, p. 182-239, 285-318). Pelo que foi aqui apresentado, podemos inferir que é flagrante o contraste entre o modelo de família defendido no discurso hegemônico amapaense (e brasileiro) e as práticas efetivas da maior parte dos homens e mulheres que viviam na região da foz do rio Amazonas. $\mathrm{O}$ repertório de práticas oferecido pelas tradições (modos de vida amazônicos) e as improvisações necessárias à luta contra a pobreza não propiciavam que a mulher empobrecida fosse frágil, dependente ou submissa. Como afirmamos anteriormente, no interior das unidades domésticas eram elaboradas as principais táticas para o enfrentamento da insegurança estrutural. Aí as mulheres desempenhavam papéis vitais e, não raro, elas eram as únicas garantidoras da manutenção familiar.

\section{FAMILY AND EVERYDAY SURVIVAL ON THE AMAZONAS ESTUARY (1944-1964)}

Abstract: This article analyses familiar survival strategies existent in Macapá, between 1944 and 1964. The focus is theimportance of the familiar solidarity to domestic unites sustenance. We emphasize that inside those unites, Macapás women frequently faceddominant expectations, besides they often assumed all members survival responsibility.

Keywords: Family. Survival. Gender. Work. Everyday Life.

\section{Notas}

${ }^{1}$ Este artigo originou-se de uma parte da tese de doutorado $A$ cidade dos trabalhadores: insegurança estrutural e táticas de sobrevivência em Macapá (19441964), elaborada sob a orientação da Dra. Maria Odila Leite da Silva Dias e defendida no Programa de Pós-Graduação em História Social da Universidade de São Paulo (USP), em 2013.

${ }^{2}$ Tal artigo - Muitos "barbados" para poucos "brotos": escassez de mulheres nos territórios brasileiros - foi transcrito no jornal Amapá. Esse jornal era produzido pelo Governo do Território Federal do Amapá com o principal objetivo de propagandear as obras e serviços realizados pelo próprio governo. 
${ }^{3}$ Entrevista realizada no dia 13 de fevereiro de 2008, por Sidney da Silva Lobato, com a Sra. Josefa Lina da Silva. Ela fez parte da comunidade negra que residia no centro histórico de Macapá e que, com as reformas urbanas ali promovidas a partir de 1944, foi transferida para os chamados Campos do Laguinho (cercania da cidade).

${ }^{4}$ Pequena cidade do arquipélago do Marajó.

\section{Referências}

\section{Artigos de Jornais:}

AMAPÁ [Inaugurado o Posto de Puericultura “Iracema Carvão Nunes”]. № 29, de 06 de outubro de 1945, p. 1.

AMAPÁ [Legião Brasileira de Assistência]. № 124, de 26 de julho de 1947, p. 2. AMAPÁ [A família]. № 167, de 22 de maio de 1948, p. 2.

AMAPÁ [O Amapá, um dos vanguardeiros da proteção à maternidade e à infância]. № 202, de 25 de janeiro de 1949, p. 10.

AMAPÁ [Posto de Puericultura "Iracema Carvão Nunes"]. № 339, de 13 de setembro de 1951a, p. 7.

AMAPÁ ["Formação de hábitos sadios na infância”: vai ser condignamente comemorada nesta capital a Semana da Criança - o programa dos festejos]. № 342, de 06 de outubro de 1951b, p. 1.

AMAPÁ [Matrimônio em sangue]. № 350, de 01 de dezembro de 1951d, p. 2.

AMAPÁ [Escola Doméstica de Macapá: aprimorando a mulher amapaense para a nobre direção do lar]. № 358, de 25 de janeiro de 1952a, p. 4.

AMAPÁ [O lar é o alicerce da família: a Escola Doméstica de Macapá cumpre e amplia suas nobres finalidades]. № 391, de 13 de setembro de 1952b, p. 4.

AMAPÁ [Muitos "barbados" para poucos "brotos": escassez de mulheres nos territórios brasileiros]. № 408, de 10 de janeiro de 1953a, p. 2.

AMAPÁ [Escola Doméstica]. № 435, de 26/04/1953b, p. 2.

AMAPÁ [Espôsa arrependida]. № 1.284, de 08 de agosto de 1964, p. 2.

A VOZ CATÓLICA [Mãe e filhos...]. № 16, de 14 de fevereiro de 1960a, p. 4.

A VOZ CATÓLICA [Mãe e educadora]. № 18, de 28 de fevereiro de 1960b, p. 4. 
A VOZ CATÓlICA [Pai... Homem econômico]. № 22, de 27 de março de 1960c, p. 4.

A VOZ CATÓLICA [Queres casar? Prepara-te]. № 19, de 06 de março de 1960d, p. 4.

A VOZ CATÓlICA [Feminismo exagerado]. № 43, de 21 de setembro de 1960e, p. 4.

A VOZ CATÓLICA [Tú és grande, mulher!]. № 14, de 31 de janeiro de 1960f, p. 4. A VOZ CATÓLICA [A esposa e a alegria do lar]. № 84, de 04 de junho de 1961, p. 2.

A VOZ CATÓLICA [S.O.S.!...]. № 202, de 08 de setembro de 1963, p. 2.

\section{Processos Judiciais:}

AFCM. Caixa 224, processo no 1474SN, de 03 de março de 1943.

AFCM. Caixa 281, processo no 046, de 13 de abril de 1945.

AFCM. Caixa 227, processo no 071, de 03 de janeiro de 1946a.

AFCM. Caixa 224, processo no 103, de 24 de agosto de 1946b.

AFCM. Caixa 227, processo no 100, de 04 de julho de 1946c.

AFCM. Caixa 243, processo no 172, de 24 de fevereiro de 1948.

AFCM. Caixa 304, processo no 283, de 22 de abril de 1949a.

AFCM. Caixa 299, processo nº 278을 de 02 de março de $1949 \mathrm{~b}$.

AFCM. Caixa 264, processo no $1399 S N$, de 10 de maio de 1952a.

AFCM. Caixa 272, processo no 647, de 17 de junho de 1952b.

AFCM. Caixa 272, processo no 668, de 18 de julho de 1952c.

AFCM. Caixa 275, processo no 649, de 18 de junho de 1952d.

AFCM. Caixa 273, processo no 273, de 13 de março de 1952e.

AFCM. Caixa 262, processo no 719 , de 23 de dezembro de $1952 \mathrm{f}$.

AFCM. Caixa 281, processo no 747, de 20 de março de 1953a.

AFCM. Caixa 281, processo no 1030 SN, de 05 de julho de 1953b.

AFCM. Caixa 276, processo no 63 , de 04 de maio de 1953c. 
Família e sobrevivência cotidiana na foz do Amazonas...

AFCM. Caixa 276, processo $\mathrm{n}^{\circ}$ 781, de 27 de maio de 1953d.

AFCM. Caixa 276, processo no 812, de 01 de agosto de 1953e.

AFCM. Caixa 225, processo no $1321 S N$, de 25 de novembro de 1957a.

AFCM. Caixa 255, processo no 1247, de 10 de outubro de 1957b.

AFCM. Caixa 276, processo no 1404, de 17 de dezembro de 1960a.

AFCM. Caixa 279, processo no 1367, de 18 de janeiro de 1960b.

AFCM. Caixa 279, processo no 1562, de 20 de julho de 1964.

\section{Referências}

ALVARES, Maria Luzia Miranda. Educação e (in)submissão feminina no Pará. In: D'INCAO, Maria Ângela; SILVEIRA, Isolda M. da (Org.). A Amazônia e a crise da modernização. Belém: Museu Paraense Emílio Goeldi, 1994. p. 213-226.

CANCELA, Cristina Donza. Casamento e relações familiares na economia da borracha. Belém (1870-1920). Tese (Doutorado em História Social)-Faculdade de Filosofia, Letras e Ciências Humanas. Universidade de São Paulo. São Paulo, 2006.

CASTRO, Fabio. Economia familiar cabocla na várzea do médio-baixo Amazonas. In: ADAMS, Cristina; MURRIETA, Rui; NEVES, Walter (Org.). Sociedades caboclas amazônicas: modernidade e invisibilidade. São Paulo: Annablume, 2006. p. 173-194.

FAISSOL, Speridião. Atlas do Amapá. Rio de Janeiro: Instituto Regional de Desenvolvimento do Amapá e Conselho Nacional de Geografia (IBGE), 1966.

INSTITUTO BRASILEIRO DE GEOGRAFIA E ESTATÍSTICA (IBGE). Brasil. Território do Amapá. Rio de Janeiro: IBGE, 1955.

. Recenciamento geral de 1960: Rondônia - Roraima - Amapá. Rio de Janeiro: IBGE, 1968.

LIMA, Deborah Magalhães. A economia doméstica em Mamirauá. In: ADAMS, Cristina; MURRIETA, Rui; NEVES, Walter (Org.). Sociedades caboclas amazônicas: modernidade e invisibilidade. São Paulo: Annablume, 2006. p. 145-172.

LOMBAERDE, Padre Júlio Maria. Macapá: sua história desde a fundação até hoje. Macapá: [s. n.], 1987. Mimeografado.

MINISTÉRIO DA EDUCAÇÃO E SAÚDE. Brasil. Nova Lei Orgânica do Ensino Secundário. Rio de Janeiro: A. Delattre e Filho, 1942. p. 7. 
MELLO, Alcino Teixeira de. Nordestinos na Amazônia. Rio de Janeiro: Imprensa Nacional, 1956.

NEGRI, Teodoro. Dom Aristides: uma aventura humana e missionária. São Paulo: Mundo e Missão, [?].

NUNES, Janary. Relatório das atividades do Governo do Território Federal do Amapá em 1944. Rio de Janeiro: Imprensa Nacional, 1946.

OLIVEIRA FILHO, João Pacheco de. O caboclo e o brabo: notas sobre duas modalidades de força de trabalho na expansão da fronteira amazônica no século XIX. Encontros com a civilização brasileira, n. 11, p. 101-140, 1979.

PEREIRA, Ricardo. A criança no Estado Novo: uma leitura na longa duração. Revista Brasileira de História, São Paulo, v. 19, n. 38, p. 165-198, 1999.

SAVAGE, Mike. Classe e história do trabalho. In: BATALHA, Claudio H. M.; SILVA, Fernando Teixeira da; FORTES, Alexandre (Org.). Culturas de classe: identidade e diversidade na formação do operariado. Campinas: UNICAMP, 2004. p. 25-48.

SCHUELER, Alessandra F. Martinez. Crianças e escolas na passagem do Império para a República. Revista Brasileira de História, São Paulo, v. 19, n. 37, p. 59-84, 1999.

SECRETO, Maria Verónica. Soldados da borracha: trabalhadores entre o sertão e a Amazônia no governo Vargas. São Paulo: Fundação Perseu Abramo, 2007. SIMONIAN, Ligia T. L. Mulheres da Amazônia brasileira: entre o trabalho e a cultura. Belém: UFPA; NAEA, 2001.

WAGLEY, Charles. Uma comunidade amazônica: estudo do homem nos trópicos. São Paulo: Editora Nacional, 1957.

Recebido em: 07/09/2014

Aprovado em: 10/01/2015 